\title{
Renal Biopsy: Use of Biomarkers as a Tool for the Diagnosis of Focal Segmental Glomerulosclerosis
}

\author{
Crislaine Aparecida da Silva, ${ }^{1}$ Mariana Molinar Mauad Cintra, ${ }^{1}$ Eliângela de Castro Côbo, ${ }^{1}$ \\ Marcos Vinícius da Silva, ${ }^{2}$ Fabiano Bichuette Custódio, ${ }^{1}$ Rosana Rosa Miranda Corrêa, ${ }^{1}$ \\ Lúcio Roberto Castellano, ${ }^{3}$ Marlene Antônia dos Reis, ${ }^{1}$ and Juliana Reis Machado ${ }^{1}$ \\ ${ }^{1}$ Pathology Laboratory, Nephropathology Service, Federal University of Triângulo Mineiro, 38015-150 Uberaba, MG, Brazil \\ ${ }^{2}$ Immunology Laboratory, Department of Biological Sciences, Federal University of Triângulo Mineiro, 58051-900 Uberaba, MG, Brazil \\ ${ }^{3}$ Human Immunology Research and Education Group, Technical Health School of UFPB, Federal University of Paraíba, \\ 38025-180 João Pessoa, PB, Brazil
}

Correspondence should be addressed to Juliana Reis Machado; julianareismachado@hotmail.com

Received 26 November 2013; Revised 15 January 2014; Accepted 15 January 2014; Published 25 February 2014

Academic Editor: Vincent Sapin

Copyright (c) 2014 Crislaine Aparecida da Silva et al. This is an open access article distributed under the Creative Commons Attribution License, which permits unrestricted use, distribution, and reproduction in any medium, provided the original work is properly cited.

Focal segmental glomerulosclerosis (FSGS) is a glomerulopathy associated with nephrotic syndrome and podocyte injury. FSGS occurs both in children and adults and it is considered the main idiopathic nephrotic syndrome nowadays. It is extremely difficult to establish a morphological diagnosis, since some biopsies lack a considerable quantifiable number of sclerotic glomeruli, given their focal aspect and the fact that FSGS occurs in less than half of the glomeruli. Therefore, many biological molecules have been evaluated as potential markers that would enhance the diagnosis of FSGS. Some of these molecules and receptors are associated with the pathogenesis of FSGS and have potential use in diagnosis.

\section{Introduction}

Focal segmental glomerulosclerosis (FSGS) is a renal disease characterized by nephrotic syndrome that accounts for $20 \%$ of cases in children and $40 \%$ of cases in adults [1,2]. Nearly from seven to fifteen percent of all children affected by idiopathic nephrotic syndrome are diagnosed with FSGS after renal biopsy. Without treatment, these patients might develop progressive proteinuria and a reduced glomerular filtration rate and about $30 \%$ of them might develop end-stage kidney disease in twenty years [3]. Given its morphological aspects, this glomerulopathy is defined as segmental due to the location of the lesions, and it is named focal because there are few glomeruli with sclerotic changes. FSGS is considered a podocytopathy mainly because of podocyte injury and the subsequent loss of such an important structure of the glomerular filtration barrier. Proteinuria is a defining clinical characteristic of focal segmental glomerulosclerosis [1].

Although some genetic mutations in podocyte genes have been linked to the occurrence of FSGS in humans, many patients develop this clinical entity without any genetic disorders, whereas other patients have proteinuria after some hours or even days after kidney transplantation. These clinical manifestations have shed some light on the hypothesis that a possible circulating factor would be involved in FSGS [4]. The concept of FSGS permeability factor is highly supported by recurrent syndrome after transplantation [5], proteinuria response to the plasmapheresis therapy [6], immunoadsorption [7], and transient nephrotic syndrome in a newborn whose mother had the disease [8].

Some studies have shown that patients with recurrent FSGS have some permeability factors on plasma that would be responsible for injuring the glomerular filtration barrier, thus causing proteinuria $[9,10]$. Among these factors, some have been receiving considerable attention: CCL1, SuPAR, and hemopexin, although the last has been better correlated to minimal change disease (MCD) [11-13].

The search for markers that could be useful as diagnostic tools for FSGS is extremely important, since few renal 
biopsies of FSGS patients have a considerable number of injured glomeruli to determine the actual diagnosis of the disease. In order to facilitate diagnosis, researchers have speculated that some markers, such as components of the glomerular basement membrane, cytokines, receptors, and matrix components, as well as their soluble forms and oxidative stress markers, could be potential future diagnostic tools for FSGS (summarized in Table 1).

\section{SuPAR}

SuPAR is the soluble form of the urokinase-type plasminogen activator receptor (UPAR), and it is expressed in several immunologically active cells. Increased serum levels are indicative of immune system activation in inflammatory conditions and infections [14], such as HIV, tuberculosis, malaria, sepsis, rheumatoid arthritis [15], and FSGS [16].

The form associated with plasma membrane (UPAR) is an important regulator of plasminogen activation and a major component of homeostasis expressed on the surface of a wide variety of cells $[17,18]$. The biological activity of SuPAR is not fully known, so it may be either an active molecule or simply the result of an increased release of uPAR on the cell surface. Nonetheless, UPAR interacts with both UPA and vitronectin, and the latter interacts with integrins in order to regulate cell motility $[19,20]$.

This receptor has also been shown to orchestrate signaling pathways by binding to other transmembrane receptors, including integrins $[21,22]$. The urokinase receptor is composed of a glycosylphosphatidylinositol- (GPI-) anchored protein with three domains that confer solubility to it when detached from the membrane by cleavage of GPI anchors [21].

SuPAR is expressed at low levels under physiological conditions in human blood and it has a known role as a circulating protein involved in neutrophil trafficking and stem cell mobilization [21, 22]. Its ability of binding to integrins is essential for activating them [27]. Integrins, in turn, might determine podocyte motility during the early manifestations of FSGS in native and posttransplant kidneys [53].

Regardless of the stimuli (via local podocyte or systemic), pathological integrin signaling in podocytes might be considered a key event in the induction of glomerular diseases associated with proteinuria [16]. However, other permeability factors may be involved, either alone or in conjunction with SuPAR, in some nephropathies such as that observed in approximately $70 \%$ of patients with membranous nephropathy who have anti-PLA2R antibodies [54].

The SuPAR receptor was evaluated as a cause of primary FSGS in different experimental models of disease, showing that SuPAR may be deposited in the glomeruli and/or bound to podocyte integrins, hence activating them to cause loss of cell function as well as detectable proteinuria [27]. A recent study identified SuPAR in plasma samples of recurrent FSGS patients. Downstream signaling pathway activation of uPAR receptor expressed in podocyte membranes causes the loss of function of these receptors and detectable proteinuria [16]. Moreover, high SuPAR serum concentrations were found in patients with primary FSGS, but not in those affected by other glomerulopathies, such as minimal change disease (MCD), membranous nephropathy, and preeclampsia [27].

Another paper, however, showed that SuPAR was elevated during primary FSGS while comparing the plasma levels of this soluble factor among patients with GESF, which may limit its usefulness to differentiate forms of this disease [23]. Moreover, this same work has shown that SuPAR levels would be also detected at high levels on patients with more severe kidney lesions as tubular atrophy, interstitial fibrosis, and inflammation cells infiltrate [23]. On the other hand, Wei et al. (2012) [24] could not correlate elevated levels of SuPAR with elevated C-reactive protein levels as an inflammatory marker during comparison made between two groups of GESF patients from distinct regions. This work also demonstrated that primary FSGS patients present high SuPAR levels independently of being adults or children [24]. These results diverge from that observed by Bock et al. (2013) [26] who demonstrated that SuPAR levels would not contribute to primary FSGS diagnosis among pediatric patients.

Despite all these evidences in the last years, it is not yet clear why FSGS patients have high circulating SuPAR levels. It has been speculated that there might be a connection between mutations in podocyte genes $[24,55]$ and an increase in some circulating permeability factors, even though these events occur by accident. On the other hand, abnormalities in podocytes might progress to a more aggressive lesion that would be responsible for an increased feedback loop between circulating molecules, thus leading to recurrent or even more severe forms of renal failure [55].

In cases of renal failure, higher serum and urine levels of proteins and more precisely of albumin seem to have a direct correlation with SuPAR levels in all kidney transplant candidates comparing to healthy controls. Nevertheless, these higher SuPAR levels seemed to not present any specificity to FSGS, albeit elevated SuPAR levels were detected in the urine of transplanted patients with recurrent FSGS [25].

Taking all these data together, we believe that the measurement of SuPAR levels might be useful diagnostic tool for primary FSGS, thus indicating its implementation in a clinical routine panel together with other biomarkers in pretransplanted patients.

\section{CLC-1}

CLC, also referred to as CLCF1 (Cardiotrophin-like cytokine factor 1), NNT-1, or BSF-3 (Neurotrophin-1/B-cell-stimulating factor-3, also known as cardiotrophin-like cytokine) are cytokines identified based on their homology with the IL-6 family $[56,57]$.

CLC is expressed in the immune system and its cDNAs could be cloned from $\mathrm{T}$ cells $[58,59]$. It is an important cytokine implicated in the development of the central nervous system [57], is involved in motor neuron development in vitro, and its transcripts are found in the skeletal muscle during massive motor neuron cell death $[60,61]$. 
TABLE 1: The potential use of different biomarkers on FSGS diagnosis.

\begin{tabular}{|c|c|c|c|}
\hline Biomarker & Species & Activity & Reference \\
\hline \multirow{3}{*}{$\begin{array}{l}\text { Soluble urokinase-type plasminogen } \\
\text { activator receptor (SuPAR) }\end{array}$} & Human & $\begin{array}{l}\text { Elevated levels in the plasma of primary FSGS patients } \\
\text { and in plasma and urine of transplanted patients with } \\
\text { recurrent FSGS }\end{array}$ & [23-25] \\
\hline & & $\begin{array}{l}\text { Still inconclusive for primary FSGS diagnosis in } \\
\text { children }\end{array}$ & {$[26]$} \\
\hline & Mice & $\begin{array}{l}\text { Causes foot process effacement, proteinuria, and } \\
\text { FSGS-like glomerulopathy by direct activation of } \\
\text { podocyte integrins }\end{array}$ & {$[16,27]$} \\
\hline $\begin{array}{l}\text { Cardiotrophin-like cytokine } \\
\text { factor } 1 \text { (CLC-1) }\end{array}$ & Human & $\begin{array}{l}\text { Elevated plasma levels in patients with recurrent FSGS, } \\
\text { mimicking the effects of FSGS plasma on Palb. } \\
\text { Anti-CLC-1- specific monoclonal antibody blocks the } \\
\text { Palb effect of active FSGS sera }\end{array}$ & {$[4,13]$} \\
\hline \multirow{5}{*}{$\begin{array}{l}\text { Transforming growth factor-beta } \\
(\mathrm{TGF}-\beta)\end{array}$} & & $\begin{array}{l}\text { Circulating plasma levels correlated with other } \\
\text { biomarkers in patients with diverse glomerulopathies }\end{array}$ & {$[28]$} \\
\hline & Human & Increased renal expression in children with FSGS & {$[29]$} \\
\hline & & $\begin{array}{l}\text { Increased expression of the protein, its receptor, and } \\
\text { associated signalling proteins in podocytes of FSGS } \\
\text { patients }\end{array}$ & {$[30]$} \\
\hline & & $\begin{array}{l}\text { In situ expression is associated with changes in } \\
\text { extracellular matrix and podocyte apoptosis }\end{array}$ & {$[31]$} \\
\hline & Mice & Induces podocyte apoptosis & {$[32]$} \\
\hline \multirow{3}{*}{ Malondialdehyde } & Human & $\begin{array}{l}\text { Potent marker of oxidative stress-induced lipid } \\
\text { peroxidation used in several acute and chronic kidney } \\
\text { diseases in adults and children }\end{array}$ & [33-35] \\
\hline & & $\begin{array}{l}\text { Elevated urine and serum levels associated with } \\
\text { glomerular overexpression in patients with FSGS }\end{array}$ & {$[36,37]$} \\
\hline & Mice & $\begin{array}{l}\text { Associated with reactive oxygen species overproduction } \\
\text { in animal glomeruli mimicking human FSGS }\end{array}$ & {$[38]$} \\
\hline \multirow{3}{*}{ Dystroglycan } & Human & $\begin{array}{l}\text { Differential expression between MCD and FSGS } \\
\text { patients }\end{array}$ & {$[39]$} \\
\hline & & $\begin{array}{l}\text { Increased expression in FSGS compared to MDC renal } \\
\text { biopsies }\end{array}$ & {$[40]$} \\
\hline & Rat & $\begin{array}{l}\text { Serves as matrix anchor to the glomerular filtration } \\
\text { membrane }\end{array}$ & {$[41]$} \\
\hline $\begin{array}{l}\text { Transient receptor potential cation } \\
\text { channel } 6 \text { (TRP6) }\end{array}$ & Human & $\begin{array}{l}\text { Fundamental component of the glomerular basement } \\
\text { membrane. Gene mutations cause inherited glomerular } \\
\text { diseases such as FSGS }\end{array}$ & {$[42,43]$} \\
\hline \multirow[t]{2}{*}{$\begin{array}{l}\text { MicroRNAs } \\
\text { (miR-192 and miR-205) }\end{array}$} & Human & $\begin{array}{l}\text { Higher serum levels in primary FSGS than MCD } \\
\text { patients. They correlate with the degree of interstitial } \\
\text { fibrosis in FSGS }\end{array}$ & {$[44]$} \\
\hline & Rat & They are mainly expressed in the renal cortex & {$[45]$} \\
\hline \multirow{4}{*}{$\begin{array}{l}\text { Metalloproteinases (MMP-2 and } \\
\text { MMP-9) and Tissue inhibitors of } \\
\text { metalloproteinases } \\
\text { (TIMPs) }\end{array}$} & Human & $\begin{array}{l}\text { Elevated plasma levels associated with kidney allograft } \\
\text { survival }\end{array}$ & {$[46]$} \\
\hline & & $\begin{array}{l}\text { Circulating plasma levels correlated with other } \\
\text { biomarkers in patients with diverse glomerulopathies }\end{array}$ & {$[28]$} \\
\hline & Mice & $\begin{array}{l}\text { Decreased expression in the kidneys of mice presenting } \\
\text { glomerulonephritis }\end{array}$ & {$[47]$} \\
\hline & Rat & $\begin{array}{l}\text { Reduced expression was associated with fibronectin } \\
\text { deposition in FSGS injured glomeruli }\end{array}$ & {$[48]$} \\
\hline \multirow[b]{2}{*}{$\begin{array}{l}\text { Human neutrophil } \\
\text { gelatinase-associated } \\
\text { lipocalin (NGAL) }\end{array}$} & & $\begin{array}{l}\text { Increase in urine and kidney cortical tubules of patients } \\
\text { with acute renal failure }\end{array}$ & {$[49-51]$} \\
\hline & Human & $\begin{array}{l}\text { Elevated levels in the urine from children with FSGS, } \\
\text { presenting positive correlation with urinary protein } \\
\text { excretion but negative correlation with estimated } \\
\text { creatinine clearance at disease diagnosis }\end{array}$ & {$[52]$} \\
\hline
\end{tabular}


The CLC-1 was identified in the active fraction by galactose affinity chromatography, and it was isolated as a protein that mediates albumin permeability (Palb). The Palb assay values vary from 0 , in normal glomeruli, to 1.0 in tissues with a maximum lesion diameter. Nearly $30 \%$ of patients with FSGS have a Palb value of 0.5 [13].

Recently, CLC-1 has been described as a soluble factor related to recurrent FSGS cases. Studies have shown that CLC-1 circulating levels in patients with recurrent FSGS may be up to 100 times higher than in normal subjects; however, its genesis still needs clarification [4]. Until now, it is known that CLC owns important neutrophilic activity, with interesting immunomodulatory effects after its interaction with the soluble receptor CLF $[56,62]$. This receptor for CLC1 seems to be intimately related to other matrix proteins, modulating the intensity of type III collagen deposition in the liver [63].

In the kidney, CLC-1 seems to increase the glomerular permeability, whereas decreasing the expression of nephrin [4]. Further studies are needed to elucidate the role of CLC-1 in FSGS pathogenesis.

\section{TGF- $\beta$}

Transforming growth factor-beta (TGF- $\beta$ ) is a multifunctional protein that controls the proliferation, differentiation, and other functions of many cell types. Many cells synthesize TGF- $\beta$ and have specific receptors for it; they also regulate, positively and negatively, many other growth factors. TGF$\beta$ plays an important role in the bone remodeling process as a potent stimulator of osteoblastic bone formation, leading to chemotaxis, proliferation, and differentiation in compromised osteoblasts. It is highly expressed in bones and abundantly expressed in articular cartilage and chondrocytes, and it is increased in osteoarthritis as well. A mutation in TGF- $\beta$ is associated with skeletal diseases such as CamuratiEngelmann disease (CED), also known as progressive diaphyseal dysplasia 1 (PDD1) [64-69].

The pathogenesis of glomerular sclerosis observed in FSGS patients may be caused by an increase in glomerular profibrotic cytokines, such as IL-13, IL-4, or TGF- $\beta$ [7073]. Increased levels of TGF- $\beta$ may be linked to the presence of intrinsic sclerosis pathways that stimulate cytokine production, such as high glomerular intracapillary pressure $[74,75]$, glomerular hypertrophy [76], and excessive protein loss through glomerular capillaries [77].

TGF- $\beta$ is a key regulator of the extracellular matrix surrounding renal cells. Its expression by podocytes might contribute to glomerular basement membrane thickness, to mesangial matrix expansion, and to apoptosis [78]. The production of TGF- $\beta$ is controlled by cell-cycle regulatory proteins. The activation of specific cyclin-dependent kinases (CDK) promotes cell proliferation. The cyclin-CDK complex is negatively regulated by CDK inhibitors p21, p27, and p57. Podocyte injury induces the loss of function of p27 and p57, resulting in uncontrolled proliferation of podocytes [31].

Furthermore, Smad 2 and Smad3 are molecules that mediate cell growth and that are activated by TGF- $\beta$ receptors.
Phosphorylated Smad2/Smad3 then form complexes with Smad 4 and move into the nucleus to transduce signals to target genes [79]. Increased expression of TGF- $\beta$, of TGF- $\beta$ receptor type II, and of phosphorylated Smad2/3 proteins is observed in podocytes of FSGS patients [30]. Nevertheless, TGF- $\beta$ itself may induce the expression of Smad7, which inhibits Smad2/3 phosphorylation in a negative feedback loop [80]. Smad7 is highly expressed in patients with clinical signs of podocyte injury. In vitro culture of podocytes in the presence of TGF- $\beta$ showed that both Smad7 and TGF-SS1 may be associated with cell apoptosis, suggesting that Smad7 has a role in progressive podocyte loss [32].

Some studies have demonstrated that increased renal expression of TGF- $\beta 1$ may be observed in children with FSGS in contrast with patients with LM. This observation suggests that the transcription of the TGF- $\beta$ gene in kidneys might predict the development of kidney failure in FSGS [29].

The increased production of TGF- $\beta$ might induce the expression of the integrin-linked kinase (ILK), a protein which is related to the pathogenesis of many nephropathies associated with proteinuria. The upregulation of ILK in podocytes might determine the occurrence of epithelialmesenchymal transition (EMT) in these cells by inducing helix-loop-helix transcription factors [81].

\section{Malondialdehyde}

Malondialdehyde (MDA) is a natural product formed in all mammalian cells as an end-product of lipid peroxidation. MDA is a highly reactive three-carbon dialdehyde and it is produced as a peroxidation product of polyunsaturated fatty acids, including the metabolism of arachidonic acid. MDA immediately binds to several functional groups of molecules, including proteins, lipoproteins, and DNA. It also reacts with DNA to form adducts to deoxyguanosine and deoxyadenosine. The major adduct to DNA is a pyrimidopurinone called M1G, which appears to be a major endogenous DNA adduct in human beings, and which may significantly lead to cancer associated with lifestyle and dietary factors. MDA-modified proteins may show altered physico chemical behavior and antigenicity. Because MDA is toxic, it has been implicated in aging, mutagenesis, carcinogenesis, diabetic nephropathy, and radiation damage. Increased expression of MDA has been observed in the brains of Alzheimer's patients [82-88].

Malondialdehyde (MDA) is an important biomarker of oxidative stress. In general, lipid peroxidation products such as malondialdehyde (MDA, $\mathrm{C} 3 \mathrm{H} 4 \mathrm{O} 2$ ) may be used as indicators of the action of free radicals in the body. MDA has cytotoxic and genotoxic activities, as well as increased levels in some diseases associated with oxidative stress; in addition, MDA quantification in biological samples accounts for an important oxidative stress parameter [33].

Biological membranes have high levels of polyunsaturated acids that make them susceptible to attack by reactive oxygen species (ROS) $[89,90]$. Antioxidants can neutralize ROS, but, in some situations in which the balance has been lost, the phenomenon of oxidative stress arises. Even though all cellular components are susceptible to the action of ROS in 
the oxidative burst, the membrane is one of the most affected targets, especially after lipid peroxidation, which alters its structure and permeability [91].

Given the challenging aspect of direct measurement of free radicals in tissues, lipid peroxidation is often used as a predictive index of ROS-mediated injuries. Malondialdehyde is a marker of oxidative stress-induced lipid peroxidation that has been regarded as the best marker for several acute and chronic kidney diseases [34, 35].

Binder and colleagues demonstrated that Mpv17 geneinactivated mice presented glomerular overproduction of oxygen radicals, which can be used as a model of FSGS in humans [38]. Higher levels of malondialdehyde were observed in urine and serum samples, as well as its glomerular overexpression in patients with FSGS in comparison with minimal change disease (MCD) $[36,37]$. Therefore, tissular expression of oxidative stress markers should be regarded as an important tool for the diagnosis of renal injury.

\section{Dystroglycan}

Dystroglycans are essential elements of the neuromuscular junction (NMJ). The dystroglycan gene is expressed as a precursor protein that is posttranslationally cleaved inside a $156 \mathrm{kDa}$ extracellular peripheral membrane protein called alpha-dystroglycan and a $43 \mathrm{kDa}$ transmembrane protein, beta-dystroglycan. The latter is a PPxY motif-containing protein that binds to a WW domain-containing protein, such as utrophin and dystrophin. Phosphorylation at tyrosine 892 within the PPxY motif can regulate $\mathrm{c}$-Src interactions with beta-dystroglycan, as well as inhibiting interaction with WW domains. Beta-dystroglycan is normally localized to the skeletal muscle cell plasma membrane; however, phosphorylation at Tyr-892 leads to localization of beta-dystroglycan to endosomal compartments along with c-Src. Therefore, phosphorylation at Tyr-892 may have a central role in altering the localization of beta-dystroglycan during NMJ formation [92-98].

In kidneys, $\alpha$-/ $\beta$-dystroglycans (DG) are matrix receptors that mechanistically serve as anchors to the glomerular filtration membrane [41]. The $\beta$-chain contains the polyanionic binding site for the cationic laminin globular domain common to several matrix proteins, such as agrin, perlecan, proteoglycans, and laminin itself $[99,100]$. The $\beta$-chain, on the other hand, binds noncovalently to the DG complex in the actin cytoskeleton [101, 102]. Regele et al. (2000) [39] observed that MCD patients had decreased $\alpha, \beta$-DG levels, whereas normal levels were found in patients with FSGS. On the other hand, despite the lower levels of 3-DG in MCD, they were increased in FSGS. Furthermore, a study evaluating the glomerular expression of DG in renal biopsies showed an increased expression of DG in FSGS cases compared with MDC cases [40].

\section{TRP6}

The transient receptor potential cation channel 6 (trpc6) is a gene located in the long arm of chromosome 11 (11q22.1) encoding a protein of the same name $[42,43]$. It is considered to be a receptor-activated nonselective calcium permanent cation channel [103]. The TRPC channels comprise a family of nonselective $\mathrm{Ca}^{2+}$ permeable cation channels that are widely expressed in vertebrate tissues [42, 43]. It is believed that members of the TRPC family are activated in response to signal transduction pathways involved in phospholipase $\mathrm{C}$ stimulation [104]. These channels have been associated with many biological functions, such as cell growth, ion homeostasis, and $\mathrm{Ca}^{2+}$ influx-dependent mechanical functions [105].

The TRPC6 channel is an important component of the glomerular basement membrane colocalized with CD2AP, nephrin, and podocin in podocytes [106]. It coimmunoprecipitates with dynamin [107], which plays an important role in membrane protein trafficking and cytoskeleton regulation. Functional interactions between channel proteins and podocins may help to determine the integrity of podocyte filtration functions in order to detect mechanical stimuli and to activate $\mathrm{Ca}^{2+}$ signaling cascades that can alter cytoskeleton dynamics [108]. TRPC6 is expressed mainly in the placenta, lungs, spleen, ovaries, and small intestine, as well as in podocytes; hence, it is a component of the glomerular slit diaphragm. Moreover, it seems to be involved in the onset of focal segmental glomerulosclerosis and focal segmental glomerulosclerosis 2 (FSGS2) [103].

The importance of TRPC6 channels in podocyte function was only suggested after the discovery that mutations in the trpc6 gene could cause inherited glomerular diseases such as FSGS $[42,43]$. Furthermore, it is hypothesized that TRPC6 mutations could alter the intracellular milieu, which, as a consequence, would induce an irreversible cell state. These observations suggest that the glomerular phenotype is the consequence of a unique role of TRPC6 in the organization of the filtration apparatus or a susceptibility of this structure to the dynamic regulation of the cytoskeleton, since patients with FSGS presenting trpc6 mutations do not usually have any other pathological phenotypes $[109,110]$.

\section{MicroRNAs (miR-192 and miR-205)}

MicroRNAs (miRNAs) seem to play physiological roles in development and in pathological processes. Several miRNAs can be found in the extracellular fluids, such as plasma, serum $[111,112]$, and urine [113], as well as tissues and cells. MicroRNAs are relatively stable, which make them ideal biomarkers for disease. Even though many miRNAs are highly expressed in several tissues, some miRNAs are organ specific [114]. Specifically, the miR-192 and miR-205 are mainly expressed in the renal cortex and are extremely relevant to renal cell biology. These miRNAs are more abundant in the kidney than in any other organ [45], and their levels are higher in the serum from patients with focal segmental glomerulosclerosis (FSGS) in relation to the serum from patients with minimal change disease (MCD), and they were also regarded as biomarkers in the differentiation between FSGS and MCD [44]. 


\section{Metalloproteinases (MMP-2 and MMP-9) and TIMPs}

Metalloproteinases are a family of zinc-dependent endopeptidases that play important roles, such as segregation of the extracellular matrix, tissue remodeling, and fibrosis in several organs, including the kidney $[115,116]$. More than 28 metalloproteinases have been described to date, and they are classified into different subgroups (collagenases, matrilysin, and stromelysin) according to their structure and function [117]. Metalloproteinase-2 (MMP-2) and metalloproteinase9 (MMP-9) are members of the gelatinase family and were demonstrated in animal models and in vitro systems as important mechanisms of fibrosis in progressive chronic kidney disease $[115,118]$. MMP-2 is normally expressed in mesangial cells, and it shows increased expression in these cells, as well as in podocytes during inflammatory states [46]. Although MMP-9 is not expressed in the glomerulus under normal conditions, it is expressed during pathological conditions [48]. Both MMP-2 and MMP-9 are highly expressed in the tubular compartment in animal models with chronic kidney disease, and they were also found in the serum of patients with chronic kidney disease [28, 46, 47, 119].

According to Korzeniecka-Kozerska et al. (2013) [120], matrix metalloproteinase-9/neutrophil gelatinase-associated lipocalin (MMP-9/NGAL) is a better marker of focal glomerulosclerosis. In hypertensive rats with glomerulosclerosis, MMP-2 is increased in the glomerulus, but MMP-9 is not $[48,121]$. In humans, MMP-2 has been described as an important intermediary in tubulointerstitial fibrosis in diabetic nephropathy [118]. MMP-9, but not MMP-2, has been found in glomerular lesions in several human kidney diseases, including nephritis in Henoch-Schönlein Purpura, IgA nephropathy, and poststreptococcal glomerulonephritis [122]. The urine of patients with FSGS has prematurely increased levels of MMPs and tissue inhibitors of metalloproteinases (TIMPs) in comparison with individuals in control groups and patients with steroid-sensitive nephrotic syndrome [123]. Catania et al. observed the same data in their study, in which they found increased levels of NGAL and of urinary MMP-9 in patients with focal segmental glomerulosclerosis in contrast with the control group. MMP9/NGAL ratio is considered an important marker of the differentiation of minimal change disease and focal segmental glomerulosclerosis in children with nephrotic syndrome [120].

\section{Human Neutrophil Gelatinase-Associated Lipocalin (NGAL)}

Also referred to as Lipocalin-2, Siderocalin, Uterocalin, and $24 p 3$ [124], neutrophil gelatinase-associated lipocalin is highly accumulated in human kidney cortical tubules and in the blood and urine after nephrotoxic and ischemic injuries $[49,50]$. NGAL is significantly increased in patients with stable, but nonprogressive, renal failure [51, 125]. Urine and plasma NGAL levels increase proportionally to severity and duration of renal injury and rapidly decrease with attenuation of renal injury [126]. In glomerular diseases, analysis of isoenzymes of NGAL demonstrates that there is an increased urinary excretion of this enzyme because of an increase in the release by renal tubular cells, and not because of the increased filtration through the damaged glomerular capillary wall [127]. Urinary NGAL can be used as an acute kidney injury marker; thus, it is a marker of disease progression in children with FSGS, and it may represent disease progression in relation to its glomerular filtration rate [52].

Despite the lack of definitive studies about the role played by this molecule in the pathogenesis of kidney diseases, this seems to be a promising marker of chronic kidney diseases, being useful for disease screening or prognosis.

\section{Conclusion}

It is extremely important to understand the role played by each of the revised molecules in FSGS pathogenesis. The establishment of a complete panel of biomarkers for FSGS diagnosis is highly desirable. We believe that components of the glomerular basal membrane and the matrix, together with specific cytokines and receptors, their soluble isoforms, and oxidative stress markers, are the best candidates chosen by nephropathology services in order to provide FSGS diagnosis.

\section{Conflict of Interests}

The authors declare that they have no conflict of interests.

\section{Acknowledgments}

This study was conducted at the Nephropathology Service of the General Pathology Division of Triângulo Mineiro Federal University, Uberaba, MG, Brazil, with Grants from Conselho Nacional de Desenvolvimento Científico e Tecnológico (CNPq), Coordenação de Aperfeiçoamento de Pessoal de Nível Superior (CAPES), Fundação de Amparo à Pesquisa do Estado de Minas Gerais (FAPEMIG), and Fundação de Ensino e Pesquisa de Uberaba (FUNEPU).

\section{References}

[1] V. D. D’Agati, F. J. Kaskel, and R. J. Falk, "Focal segmental glomerulosclerosis," The New England Journal of Medicine, vol. 365, no. 25, pp. 2398-2411, 2011.

[2] C. Schell and T. B. Huber, "New players in the pathogenesis of focal segmental glomerulosclerosis," Nephrology Dialysis Transplantation, vol. 27, no. 9, pp. 3406-3412, 2012.

[3] M. Wehrmann, A. Bohle, H. Held, G. Schumm, H. Kendziorra, and H. Pressler, "Long-term prognosis of focal sclerosing glomerulonephritis. An analysis of 250 cases with particular regard to tubulointerstitial changes," Clinical Nephrology, vol. 33, no. 3, pp. 115-122, 1990.

[4] V. J. Savin, E. T. McCarthy, R. Sharma, D. Charba, and M. Sharma, "Galactose binds to focal segmental glomerulosclerosis permeability factor and inhibits its activity," Translational Research, vol. 151, no. 6, pp. 288-292, 2008. 
[5] P. F. Hoyer, B. Rodeck, M. Scherbring et al., "Development of liver size and perfusion after reduced-size liver transplantation in children," Pediatric Transplantation, vol. 5, no. 3, pp. 192-197, 2001.

[6] M. L. Artero, R. Sharma, V. J. Savin, and F. Vincenti, "Plasmapheresis reduces proteinuria and serum capacity to injure glomeruli in patients with recurrent focal glomerulosclerosis," American Journal of Kidney Diseases, vol. 23, no. 4, pp. 574-581, 1994.

[7] M. Haas, Y. Godfrin, R. Oberbauer et al., "Plasma immunadsorption treatment in patients with primary focal and segmental glomerulosclerosis," Nephrology Dialysis Transplantation, vol. 13, no. 8, pp. 2013-2016, 1998.

[8] M. J. Kemper, G. Wolf, and D. E. Müller-Wiefel, "Transmission of glomerular permeability factor from a mother to her child," The New England Journal of Medicine, vol. 344, no. 5, pp. 386387, 2001.

[9] J. Dantal, E. Bigot, W. Bogers et al., "Effect of plasma protein adsorption on protein excretion in kidney- transplant recipients with recurrent nephrotic syndrome," The New England Journal of Medicine, vol. 330, no. 1, pp. 7-14, 1994.

[10] G. M. Ghiggeri, M. Artero, M. Carraro et al., "Glomerular albumin permeability as an in vitro model for characterizing the mechanism of focal glomerulosclerosis and predicting posttransplant recurrence," Pediatric Transplantation, vol. 8, no. 4, pp. 339-343, 2004.

[11] R. Coppo, "Different targets for treating focal segmental glomerular sclerosis," Contributions to Nephrology, vol. 181, pp. 84-90, 2013.

[12] W. W. Bakker, C. M. L. van Dael, L. J. W. M. Pierik et al., "Altered activity of plasma hemopexin in patients with minimal change disease in relapse," Pediatric Nephrology, vol. 20, no. 10, pp. 14101415, 2005.

[13] E. T. McCarthy, M. Sharma, and V. J. Savin, "Circulating permeability factors in idiopathic nephrotic syndrome and focal segmental glomerulosclerosis," Clinical Journal of the American Society of Nephrology, vol. 5, no. 11, pp. 2115-2121, 2010.

[14] A. Koch, S. Voigt, C. Kruschinski et al., "Circulating soluble urokinase plasminogen activator receptor is stably elevated during the first week of treatment in the intensive care unit and predicts mortality in critically ill patients," Critical Care, vol. 15, no. 1, article R63, 2011.

[15] M. Hillman and M. Olsson-Landin, "Soluble urokinaseplasminogen activator receptor (suPAR) and natural phosphorylcholine IgM antibodies in patients at clinical onset of diabetes mellitus," Journal of Diabetes Mellitus, vol. 1, no. 4, pp. 96-103, 2011.

[16] C. Wei, C. C. Möller, M. M. Altintas et al., "Modification of kidney barrier function by the urokinase receptor," Nature Medicine, vol. 14, no. 1, pp. 55-63, 2008.

[17] R. Krishnan, M. Kremen, J. H. Hu et al., "Level of macrophage uPA expression is an important determinant of atherosclerotic lesion growth in apoe-/- mice," Arteriosclerosis, Thrombosis, and Vascular Biology, vol. 29, no. 11, pp. 1737-1744, 2009.

[18] A. Mondino and F. Blasi, "uPA and UPAR in fibrinolysis, immunity and pathology," Trends in Immunology, vol. 25, no. 8, pp. 450-455, 2004.

[19] Y. Wei, M. Lukashev, D. I. Simon et al., "Regulation of integrin function by the urokinase receptor," Science, vol. 273, no. 5281, pp. 1551-1555, 1996.
[20] Y. Wei, R.-P. Czekay, L. Robillard et al., "Regulation of $\alpha 5 \beta 1$ integrin conformation and function by urokinase receptor binding," Journal of Cell Biology, vol. 168, no. 3, pp. 501-511, 2005.

[21] F. Blasi and P. Carmeliet, "uPAR: a versatile signalling orchestrator," Nature Reviews Molecular Cell Biology, vol. 3, no. 12, pp. 932-943, 2002.

[22] H. W. Smith and C. J. Marshall, "Regulation of cell signalling by uPAR," Nature Reviews Molecular Cell Biology, vol. 11, no. 1, pp. 23-36, 2010.

[23] J. Huang, G. Liu, Y. M. Zhang et al., "Plasma soluble urokinase receptor levels are increased but do not distinguish primary from secondary focal segmental glomerulosclerosis," Kidney International, vol. 84, no. 2, pp. 366-372, 2013.

[24] C. Wei, H. Trachtman, J. Li et al., "Circulating suPAR in two cohorts of primary FSGS," Journal of the American Society of Nephrology, vol. 23, no. 12, pp. 2051-2059, 2012.

[25] C. R. Franco Palacios, J. C. Lieske, H. M. Wadei et al., "Urine but not serum soluble urokinase receptor (suPAR) may identify cases of recurrent FSGS in kidney transplant candidates," Transplantation, vol. 96, no. 4, pp. 394-399, 2013.

[26] M. E. Bock, H. E. Price, L. Gallon, and C. B. Langman, "Serum soluble urokinase-type plasminogen activator receptor levels and idiopathic FSGS in children: a single-center report," Clinical Journal of the American Society of Nephrology, vol. 8, no. 8, pp. 1304-1311, 2013.

[27] C. Wei, S. El Hindi, J. Li et al., "Circulating urokinase receptor as a cause of focal segmental glomerulosclerosis," Nature Medicine, vol. 17, no. 8, pp. 952-960, 2011.

[28] B. Bauvois, N. Mothu, J. Nguyen, T. Nguyen-Khoa, L.-H. Nöel, and P. Jungers, "Specific changes in plasma concentrations of matrix metalloproteinase- 2 and -9, TIMP-1 and TGF- $\beta 1$ in patients with distinct types of primary glomerulonephritis," Nephrology Dialysis Transplantation, vol. 22, no. 4, pp. 1115-1122, 2007.

[29] J. Strehlau, A. D. Schachter, M. Pavlakis, A. Singh, A. Tejani, and T. B. Strom, "Activated intrarenal transcription of CTL-effectors and TGF- $\beta 1$ in children with focal segmental glomerulosclerosis," Kidney International, vol. 61, no. 1, pp. 90-95, 2002.

[30] J. H. Kim, B. K. Kim, K. C. Moon, H. K. Hong, and H. S. Lee, "Activation of the TGF- $\beta /$ Smad signaling pathway in focal segmental glomerulosclerosis," Kidney International, vol. 64, no. 5, pp. 1715-1721, 2003.

[31] S. Wang, J. H. Kim, K. C. Moon, H. K. Hong, and H. S. Lee, "Cell-Cycle Mechanisms Involved in Podocyte Proliferation in Cellular Lesion of Focal Segmental Glomerulosclerosis," American Journal of Kidney Diseases, vol. 43, no. 1, pp. 19-27, 2004.

[32] M. Schiffer, M. Bitzer, I. S. D. Roberts et al., "Apoptosis in podocytes induced by TGF- $\beta$ and Smad7," Journal of Clinical Investigation, vol. 108, no. 6, pp. 807-816, 2001.

[33] M. V. Antunes, C. Lazzaretti, G. D. Gamaro, and R. Linden, "Estudo pré-analítico e de validação para determinação de malondialdeído em plasma humano por cromatografia líquida de alta eficiência, após derivatização com 2, 4dinitrofenilhidrazina," Revista Brasileira De Ciências Farmacêuticas, vol. 44, pp. 279-287, 2008.

[34] R. Agarwal, "Chronic kidney disease is associated with oxidative stress independent of hypertension," Clinical Nephrology, vol. 61, no. 6, pp. 377-383, 2004. 
[35] A. Ece, S. Kelekçi, H. Kocamaz et al., "Antioxidant enzyme activities, lipid peroxidation, and total antioxidant status in children with Henoch-Schönlein purpura," Clinical rheumatology, vol. 27, no. 2, pp. 163-169, 2008.

[36] H.-T. Kuo, M.-C. Kuo, Y.-W. Chiu, J.-M. Chang, J.-Y. Guh, and H.-C. Chen, "Increased glomerular and extracellular malondialdehyde levels in patients and rats with focal segmental glomerulosclerosis," European Journal of Clinical Investigation, vol. 35, no. 4, pp. 245-250, 2005.

[37] S. T. Nezhad, B. Momeni, and M. Basiratnia, "Glomerular malondialdehyde levels in patients with focal and segmental glomerulosclerosis and minimal change disease," Saudi Journal of Kidney Diseases and Transplantation, vol. 21, no. 5, pp. 886891, 2010.

[38] C. J. Binder, H. Weiher, M. Exner, and D. Kerjaschki, "Glomerular overproduction of oxygen radicals in Mpvl7 geneinactivated mice causes podocyte foot process flattening and proteinuria. A model of steroid-resistant nephrosis sensitive to radical scavenger therapy," American Journal of Pathology, vol. 154, no. 4, pp. 1067-1075, 1999.

[39] H. M. Regele, E. Fillipovic, B. Langer et al., "Glomerular expression of dystroglycans is reduced in minimal change nephrosis but not in focal segmental glomerulosclerosis," Journal of the American Society of Nephrology, vol. 11, no. 3, pp. 403-412, 2000.

[40] G. Giannico, H. Yang, E. G. Neilson, and A. B. Fogo, "Dystroglycan in the diagnosis of FSGS," Clinical Journal of the American Society of Nephrology, vol. 4, no. 11, pp. 1747-1753, 2009.

[41] K. Kojima and D. Kerjaschki, "Is podocyte shape controlled by the dystroglycan complex?" Nephrology Dialysis Transplantation, vol. 17, supplement 9, pp. 23-24, 2002.

[42] J. Reiser, K. R. Polu, C. C. Möller et al., “TRPC6 is a glomerular slit diaphragm-associated channel required for normal renal function," Nature Genetics, vol. 37, no. 7, pp. 739-744, 2005.

[43] M. P. Winn, P. J. Conlon, K. L. Lynn et al., "Medicine: a mutation in the TRPC6 cation channel causes familial focal segmental glomerulosclerosis," Science, vol. 308, no. 5729, pp. 1801-1804, 2005.

[44] X. Cai, Z. Xia, C. Zhang et al., "Serum microRNAs levels in primary focal segmental glomerulosclerosis," Pediatric Nephrology, vol. 28, no. 9, pp. 1797-1801, 2013.

[45] Z. Tian, A. S. Greene, J. L. Pietrusz, I. R. Matus, and M. Liang, "MicroRNA-target pairs in the rat kidney identified by microRNA microarray, proteomic, and bioinformatic analysis," Genome Research, vol. 18, no. 3, pp. 404-411, 2008.

[46] H.-R. Chang, W.-H. Kuo, Y.-S. Hsieh et al., "Circulating matrix metalloproteinase-2 is associated with cystatin $\mathrm{C}$ level, posttransplant duration, and diabetes mellitus in kidney transplant recipients," Translational Research, vol. 151, no. 4, pp. 217-223, 2008.

[47] K. Uchio-Yamada, N. Manabe, Y. Goto et al., "Decreased expression of matrix metalloproteinases and tissue inhibitors of metalloproteinase in the kidneys of hereditary nephrotic (ICGN) mice," Journal of Veterinary Medical Science, vol. 67, no. 1, pp. 35-41, 2005.

[48] S. Liu, Y. Li, H. Zhao et al., "Increase in extracellular crosslinking by tissue transglutaminase and reduction in expression of MMP-9 contribute differentially to focal segmental glomerulosclerosis in rats," Molecular and Cellular Biochemistry, vol. 284, no. 1-2, pp. 9-17, 2006.

[49] J. Mishra, C. Dent, R. Tarabishi et al., "Neutrophil gelatinaseassociated lipocalin (NGAL) as a biomarker for acute renal injury after cardiac surgery," The Lancet, vol. 365, no. 9466, pp. 1231-1238, 2005.

[50] K. Mori, H. T. Lee, D. Rapoport et al., "Endocytic delivery of lipocalin-siderophore-iron complex rescues the kidney from ischemia-reperfusion injury," Journal of Clinical Investigation, vol. 115, no. 3, pp. 610-621, 2005.

[51] M. Bennett, C. L. Dent, Q. Ma et al., "Urine NGAL predicts severity of acute kidney injury after cardiac surgery: a prospective study," Clinical Journal of the American Society of Nephrology, vol. 3, no. 3, pp. 665-673, 2008.

[52] D. M. Youssef and A. A. El-Shal, "Urine neutrophil gelatinaseassociated lipocalin and kidney injury in children with focal segmental glomerulosclerosis," Iranian Journal of Kidney Diseases, vol. 6, no. 5, pp. 355-360, 2012.

[53] J. Reiser, C. Wei, and J. Tumlin, "Soluble urokinase receptor and focal segmental glomerulosclerosis," Current Opinion in Nephrology and Hypertension, vol. 21, no. 4, pp. 428-432, 2012.

[54] L. H. Beck Jr., R. G. B. Bonegio, G. Lambeau et al., "M-type phospholipase A2 receptor as target antigen in idiopathic membranous nephropathy," The New England Journal of Medicine, vol. 361, no. 1, pp. 11-21, 2009.

[55] S. Sever, H. Trachtman, C. Wei, and J. Reiser, "Is there clinical value in measuring suPAR levels in FSGS?" Clinical Journal of the American Society of Nephrology, vol. 8, no. 8, pp. 1273-1275, 2013.

[56] G. C. A. Elson, E. Lelièvre, C. Guillet et al., "CLF associates with CLC to form a functional heteromeric ligand for the CNTF receptor complex," Nature Neuroscience, vol. 3, no. 9, pp. 867$872,2000$.

[57] G. Senaldi, B. C. Varnum, C. S. Ulla Sarmiento et al., "Novel neurotrophin-1/B cell-stimulating factor-3: a cytokine of the IL6 family," Proceedings of the National Academy of Sciences of the United States of America, vol. 96, no. 20, pp. 11458-11463, 1999.

[58] G. C. A. Elson, P. Graber, C. Losberger et al., "Cytokinelike factor-1, a novel soluble protein, shares homology with members of the cytokine type I receptor family," Journal of Immunology, vol. 161, no. 3, pp. 1371-1379, 1998.

[59] Y. Shi, W. Wang, P. A. Yourey et al., "Computational EST database analysis identifies a novel member of the neuropoietic cytokine family," Biochemical and Biophysical Research Communications, vol. 262, no. 1, pp. 132-138, 1999.

[60] D. Derouet, F. Rousseau, F. Alfonsi et al., "Neuropoietin, a new IL-6-related cytokine signaling through the ciliary neurotrophic factor receptor," Proceedings of the National Academy of Sciences of the United States of America, vol. 101, no. 14, pp. 4827-4832, 2004.

[61] J. F. Bazan, "Neuropoietic cytokines in the hematopoietic fold," Neuron, vol. 7, no. 2, pp. 197-208, 1991.

[62] F. Rousseau, J.-F. Gauchat, J. G. McLeod et al., "Inactivation of cardiotrophin-like cytokine, a second ligand for ciliary neurotrophic factor receptor, leads to cold-induced sweating syndrome in a patient," Proceedings of the National Academy of Sciences of the United States of America, vol. 103, no. 26, pp. 10068-10073, 2006.

[63] L. Stefanovic and B. Stefanovic, "Role of cytokine receptor-like factor 1 in hepatic stellate cells and fibrosis," World Journal of Hepatology, vol. 4, no. 12, pp. 356-364, 2012.

[64] X.-L. Xie, M. Wei, A. Kakehashi, S. Yamano, M. Tajiri, and H. Wanibuchi, "2-amino-3-methylimidazo[4,5-f]quinoline (iq) 
promotes mouse hepatocarcinogenesis by activating transforming growth factor- $\beta$ and Wnt/ $\beta$-catenin signaling pathways," Toxicological Sciences, vol. 125, no. 2, pp. 392-400, 2012.

[65] L. E. Becker, N. Koleganova, G. Piecha et al., "Effect of paricalcitol and calcitriol on aortic wall remodeling in uninephrectomized ApoE knockout mice," American Journal of Physiology_Renal Physiology, vol. 300, no. 3, pp. F772-F782, 2011.

[66] S. Nakamaki, H. Satoh, A. Kudoh, Y. Hayashi, H. Hirai, and T. Watanabe, "Adiponectin reduces proteinuria in streptozotocininduced diabetic wistar rats," Experimental Biology and Medicine, vol. 236, no. 5, pp. 614-620, 2011.

[67] S. Marwitz, M. Abdullah, C. Vock et al., "HOPE-BAL: improved molecular diagnostics by application of a novel technique for fixation and paraffin embedding," Journal of Histochemistry and Cytochemistry, vol. 59, no. 6, pp. 601-614, 2011.

[68] J.-X. Yin, J.-L. Tu, H.-J. Lin et al., "Centrally administered pertussis toxin inhibits microglia migration to the spinal cord and prevents dissemination of disease in an EAE mouse model," PLoS ONE, vol. 5, no. 8, Article ID e12400, 2010.

[69] V. J. Vieira, A. J. D’Acampora, A. B. W. Marcos et al., "Vascular endothelial growth factor overexpression positively modulates the characteristics of periprosthetic tissue of polyurethanecoated silicone breast implant in rats," Plastic and Reconstructive Surgery, vol. 126, no. 6, pp. 1899-1910, 2010.

[70] H.-K. Yap, W. Cheung, B. Murugasu, S.-K. Sim, C.-C. Seah, and S. C. Jordan, "Th1 and Th2 cytokine mRNA profiles in childhood nephrotic syndrome: evidence for increased IL-13 mRNA expression in relapse," Journal of the American Society of Nephrology, vol. 10, no. 3, pp. 529-537, 1999.

[71] L. le Berre, C. Hervé, F. Buzelen, C. Usal, J.-P. Soulillou, and J. Dantal, "Renal macrophage activation and Th2 polarization precedes the development of nephrotic syndrome in Buffalo/Mna rats," Kidney International, vol. 68, no. 5, pp. 20792090, 2005.

[72] K.-W. Lai, C.-L. Wei, L.-K. Tan et al., "Overexpression of interleukin-13 induces minimal-change-like nephropathy in rats," Journal of the American Society of Nephrology, vol. 18, no. 5, pp. 1476-1485, 2007.

[73] R. L. Pereira, V. O. Reis, P. Semedo et al., "Invariant natural killer $\mathrm{T}$ cell agonist modulates experimental focal and segmental glomerulosclerosis," PLoS ONE, vol. 7, no. 3, Article ID e32454, 2012.

[74] B. M. Brenner, T. W. Meyer, and T. H. Hostetter, "Dietary protein intake and the progressive nature of kidney disease: the role of hemodynamically mediated glomerular injury in the pathogenesis of progressive glomerular sclerosis in aging, renal ablation, and intrinsic renal disease," The New England Journal of Medicine, vol. 307, no. 11, pp. 652-659, 1982.

[75] S. Anderson, T. W. Meyer, H. G. Rennke, and B. M. Brenner, "Control of glomerular hypertension limits glomerular injury in rats with reduced renal mass," Journal of Clinical Investigation, vol. 76, no. 2, pp. 612-619, 1985.

[76] J. W. U. Fries, D. J. Sandstrom, T. W. Meyer, and H. G. Rennke, "Glomerular hypertrophy and epithelial cell injury modulate progressive glomerulosclerosis in the rat," Laboratory Investigation, vol. 60, no. 2, pp. 205-218, 1989.

[77] A. Remuzzi, S. Puntorieri, C. Battaglia, T. Bertani, and G. Remuzzi, "Angiotensin converting enzyme inhibition ameliorates glomerular filtration of macromolecules and water and lessens glomerular injury in the rat," Journal of Clinical Investigation, vol. 85, no. 2, pp. 541-549, 1990.

[78] H. S. Lee, "Pathogenic role of TGF- $\beta$ in the progression of podocyte diseases," Histology and Histopathology, vol. 26, no. 1, pp. 107-116, 2011.

[79] K. Miyazono, P. Ten Dijke, and C.-H. Heldin, “TGF- $\beta$ signaling by Smad proteins," Advances in Immunology, vol. 75, pp. 115-157, 2000.

[80] J. Massagué and D. Wotton, "Transcriptional control by the TGF- $\beta$ /Smad signaling system," The EMBO Journal, vol. 19, no. 8, pp. 1745-1754, 2000.

[81] Y. S. Kang, Y. Li, C. Dai, L. P. Kiss, C. Wu, and Y. Liu, "Inhibition of integrin-linked kinase blocks podocyte epithelialmesenchymal transition and ameliorates proteinuria," Kidney International, vol. 78, no. 4, pp. 363-373, 2010.

[82] X. Kong, Y. Zhang, H. B. Wu, F. X. Li, D. Y. Zhang, and Q. Su, "Combination therapy with losartan and pioglitazone additively reduces renal oxidative and nitrative stress induced by chronic high fat, sucrose, and sodium intake," Oxidative Medicine and Cellular Longevity, vol. 2012, Article ID 856085, 9 pages, 2012.

[83] B.-Y. Chen, D. P.-C. Lin, C.-Y. Wu et al., "Dietary zerumbone prevents mouse cornea from UVB-induced photokeratitis through inhibition of NF- $\kappa \mathrm{B}$, iNOS, and TNF- $\alpha$ expression and reduction of MDA accumulation," Molecular Vision, vol. 17, pp. 854-863, 2011.

[84] G. M. Denicola, F. A. Karreth, T. J. Humpton et al., "Oncogeneinduced Nrf2 transcription promotes ROS detoxification and tumorigenesis," Nature, vol. 475, no. 7354, pp. 106-109, 2011.

[85] F. Neria, M. A. Castilla, R. F. Sanchez et al., "Inhibition of JAK2 protects renal endothelial and epithelial cells from oxidative stress and cyclosporin A toxicity," Kidney International, vol. 75, no. 2, pp. 227-234, 2009.

[86] L.-W. Fan, H. J. Mitchell, L.-T. Tien, P. G. Rhodes, and Z. Cai, "Interleukin- $1 \beta$-induced brain injury in the neonatal rat can be ameliorated by $\alpha$-phenyl-n-tert-butyl-nitrone," Experimental Neurology, vol. 220, no. 1, pp. 143-153, 2009.

[87] L.-W. Fan, H. J. Mitchell, P. G. Rhodes, and Z. Cai, “ $\alpha$-Phenyl-ntert-butyl-nitrone attenuates lipopolysaccharide-induced neuronal injury in the neonatal rat brain," Neuroscience, vol. 151, no. 3, pp. 737-744, 2008.

[88] M. Mancuso, G. Davidzon, R. M. Kurlan et al., "Hereditary ferritinopathy: a novel mutation, its cellular pathology, and pathogenetic insights," Journal of Neuropathology and Experimental Neurology, vol. 64, no. 4, pp. 280-294, 2005.

[89] B. Chance, H. Sies, and A. Boveris, "Hydroperoxide metabolism in mammalian organs," Physiological Reviews, vol. 59, no. 3, pp. 527-605, 1979.

[90] J.-M. Chang, M.-C. Kuo, H.-T. Kuo, Y.-W. Chiu, and H.-C. Chen, "Increased glomerular and extracellular malondialdehyde levels in patients and rats with diabetic nephropathy," Journal of Laboratory and Clinical Medicine, vol. 146, no. 4, pp. 210-215, 2005.

[91] A. L. Ferreira and L. S. Matsubara, "Free radicals: concepts, associated diseases, defense system and oxidative stress," Revista da Associação Médica Brasileira, vol. 43, no. 1, pp. 61-68, 1997.

[92] M. Shimojima, U. Ströher, H. Ebihara, H. Feldmann, and Y. Kawaoka, "Identification of cell surface molecules involved in dystroglycan-independent Lassa virus cell entry," Journal of Virology, vol. 86, no. 4, pp. 2067-2078, 2012. 
[93] D. Takawira, G. R. S. Budinger, S. B. Hopkinson, and J. C. R. Jones, "A dystroglycan/plectin scaffold mediates mechanical pathway bifurcation in lung epithelial cells," Journal of Biological Chemistry, vol. 286, no. 8, pp. 6301-6310, 2011.

[94] Z. Zhang, P. Zhang, and H. Hu, "Large expression augments the glycosylation of glycoproteins in addition to $\alpha$-dystroglycan conferring laminin binding," PLoS ONE, vol. 6, no. 4, Article ID e19080, 2011.

[95] E. Zanoteli, D. V. de Vlekkert, E. J. Bonten et al., "Muscle degeneration in neuraminidase 1-deficient mice results from infiltration of the muscle fibers by expanded connective tissue," Biochimica et Biophysica Acta, vol. 1802, no. 7-8, pp. 659-672, 2010.

[96] L. Khouzami, M.-C. Bourin, C. Christov et al., "Delayed cardiomyopathy in dystrophin deficient $\mathrm{mdx}$ mice relies on intrinsic glutathione resource," American Journal of Pathology, vol. 177, no. 3, pp. 1356-1364, 2010.

[97] K. Schlie, A. Maisa, F. Freiberg, A. Groseth, T. Strecker, and W. Garten, "Viral protein determinants of Lassa virus entry and release from polarized epithelial cells," Journal of Virology, vol. 84, no. 7, pp. 3178-3188, 2010.

[98] V. T. Ribeiro-Resende, M. L. Ribeiro-Guimarães, R. M. Rodrigues Lemes et al., "Involvement of 9-O-acetyl GD3 ganglioside in Mycobacterium leprae infection of schwann cells," Journal of Biological Chemistry, vol. 285, no. 44, pp. 3408634096, 2010.

[99] S. H. Gee, F. Montanaro, M. H. Lindenbaum, and S. Carbonetto, "Dystroglycan- $\alpha$, a dystrophin-associated glycoprotein, is a functional agrin receptor," Cell, vol. 77, no. 5, pp. 675-686, 1994.

[100] R. Timpl, D. Tisi, J. F. Talts, Z. Andac, T. Sasaki, and E. Hohenester, "Structure and function of laminin LG modules," Matrix Biology, vol. 19, no. 4, pp. 309-317, 2000.

[101] C. J. Ilse Raats, J. van den Born, M. A. H. Bakker et al., "Expression of agrin, dystroglycan, and utrophin in normal renal tissue and in experimental glomerulopathies," American Journal of Pathology, vol. 156, no. 5, pp. 1749-1765, 2000.

[102] J. L. Ilsley, M. Sudol, and S. J. Winder, "The WW domain: linking cell signalling to the membrane cytoskeleton," Cellular Signalling, vol. 14, no. 3, pp. 183-189, 2002.

[103] K. Itsuki, Y. Imai, Y. Okamura, K. Abe, R. Inoue, and M. X. Mori, "Voltage-sensing phosphatase reveals temporal regulation of TRPC3/C6/C7 channels by membrane phosphoinositides," Channels, vol. 6, no. 3, pp. 206-209, 2012.

[104] M. Trebak, L. Lemonnier, J. T. Smyth, G. Vazquez, and J. W. Putney Jr., "Phospholipase C-coupled receptors and activation of TRPC channels," Handbook of Experimental Pharmacology, no. 179, pp. 593-614, 2007.

[105] C. Montell, “The TRP superfamily of cation channels," Science's STKE, vol. 2005, no. 272, p. re3, 2005.

[106] N. Mukerji, T. V. Damodaran, and M. P. Winn, "TRPC6 and FSGS: the latest TRP channelopathy," Biochimica et Biophysica Acta, vol. 1772, no. 8, pp. 859-868, 2007.

[107] M. Goel, W. Sinkins, A. Keightley, M. Kinter, and W. P. Schilling, "Proteomic analysis of TRPC5- and TRPC6-binding partners reveals interaction with the plasmalemmal $\mathrm{Na}+\mathrm{K}+$-ATPase," Pflugers Archiv European Journal of Physiology, vol. 451, no. 1, pp. 87-98, 2005.

[108] W. Kriz, M. Elger, P. Mundel, and K. V. Lemley, "Structurestabilizing forces in the glomerular tuft," Journal of the American Society of Nephrology, vol. 5, no. 10, pp. 1731-1739, 1995.
[109] A. Dietrich, M. Mederos y Schnitzler, H. Kalwa, U. Storch, and T. Gudermann, "Functional characterization and physiological relevance of the TRPC3/6/7 subfamily of cation channels," Naunyn-Schmiedeberg's Archives of Pharmacology, vol. 371, no. 4, pp. 257-265, 2005.

[110] N. Weissmann, A. Dietrich, B. Fuchs et al., "Classical transient receptor potential channel 6 (TRPC6) is essential for hypoxic pulmonary vasoconstriction and alveolar gas exchange," Proceedings of the National Academy of Sciences of the United States of America, vol. 103, no. 50, pp. 19093-19098, 2006.

[111] M. A. Cortez and G. A. Calin, "MicroRNA identification in plasma and serum: a new tool to diagnose and monitor diseases," Expert Opinion on Biological Therapy, vol. 9, no. 6, pp. 703-711, 2009.

[112] P. S. Mitchell, R. K. Parkin, E. M. Kroh et al., "Circulating microRNAs as stable blood-based markers for cancer detection," Proceedings of the National Academy of Sciences of the United States of America, vol. 105, no. 30, pp. 10513-10518, 2008.

[113] M. Hanke, K. Hoefig, H. Merz et al., "A robust methodology to study urine microRNA as tumor marker: microRNA-126 and microRNA-182 are related to urinary bladder cancer," Urologic Oncology, vol. 28, no. 6, pp. 655-661, 2010.

[114] Y. Liang, D. Ridzon, L. Wong, and C. Chen, "Characterization of microRNA expression profiles in normal human tissues," $B M C$ Genomics, vol. 8, article 166, 2007.

[115] J. Keeling and G. A. Herrera, "Human matrix metalloproteinases: characteristics and pathologic role in altering mesangial homeostasis," Microscopy Research and Technique, vol. 71, no. 5, pp. 371-379, 2008.

[116] J. M. Catania, G. Chen, and A. R. Parrish, "Role of matrix metalloproteinases in renal pathophysiologies," American Journal of Physiology -Renal Physiology, vol. 292, no. 3, pp. F905-F911, 2007.

[117] C. Tallant, A. Marrero, and F. X. Gomis-Rüth, "Matrix metalloproteinases: fold and function of their catalytic domains," Biochimica et Biophysica Acta, vol. 1803, no. 1, pp. 20-28, 2010.

[118] K. M. Thrailkill, R. Clay Bunn, and J. L. Fowlkes, "Matrix metalloproteinases: their potential role in the pathogenesis of diabetic nephropathy," Endocrine, vol. 35, no. 1, pp. 1-10, 2009.

[119] W.-H. Liu, N.-N. Tang, and Q.-D. Zhang, "Could mycophenolate mofetil combined with benazapril delay tubulointerstitial fibrosis in 5/6 nephrectomized rats?" Chinese Medical Journal, vol. 122, no. 2, pp. 199-204, 2009.

[120] A. Korzeniecka-Kozerska, A. Wasilewska, E. Tenderenda, A. Sulik, and K. Cybulski, "Urinary MMP-9/NGAL ratio as a potential marker of FSGS in nephrotic children," Disease Markers, vol. 34, no. 5, pp. 357-362, 2013.

[121] J. Bolbrinker, S. Markovic, M. Wehland, W. B. W. H. Melenhorst, H. van Goor, and R. Kreutz, "Expression and response to angiotensin-converting enzyme inhibition of matrix metalloproteinases 2 and 9 in renal glomerular damage in young transgenic rats with renin-dependent hypertension," Journal of Pharmacology and Experimental Therapeutics, vol. 316, no. 1, pp. 8-16, 2006.

[122] M. Urushihara, S. Kagami, T. Kuhara, T. Tamaki, and Y. Kuroda, "Glomerular distribution and gelatinolytic activity of matrix metalloproteinases in human glomerulonephritis," Nephrology Dialysis Transplantation, vol. 17, no. 7, pp. 1189-1196, 2002.

[123] K. A. Czech, M. Bennett, and P. Devarajan, "Distinct metalloproteinase excretion patterns in focal segmental glomerulosclerosis," Pediatric Nephrology, vol. 26, no. 12, pp. 2179-2184, 2011. 
[124] D. R. Flower, "The lipocalin protein family: structure and function," Biochemical Journal, vol. 318, part 1, pp. 1-14, 1996.

[125] T. McCormick and R. Venn, "Recently published papers: tracheostomy: why rather than when? Obesity: does it matter? And stroke: diagnosis, thrombosis and prognosis," Critical Care, vol. 11, no. 2, article 127, 2007.

[126] K. Tryggvason and E. Pettersson, "Causes and consequences of proteinuria: the kidney filtration barrier and progressive renal failure," Journal of Internal Medicine, vol. 254, no. 3, pp. 216-224, 2003.

[127] B. Hultberg and U. Ravnskov, "The excretion of N-acetyl- $\beta$ glucosaminidase in glomerulonephritis," Clinical Nephrology, vol. 15, no. 1, pp. 33-38, 1981. 


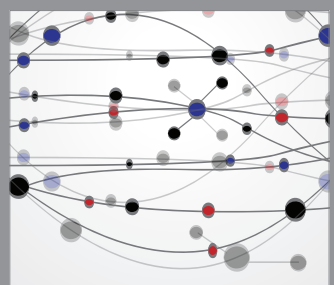

The Scientific World Journal
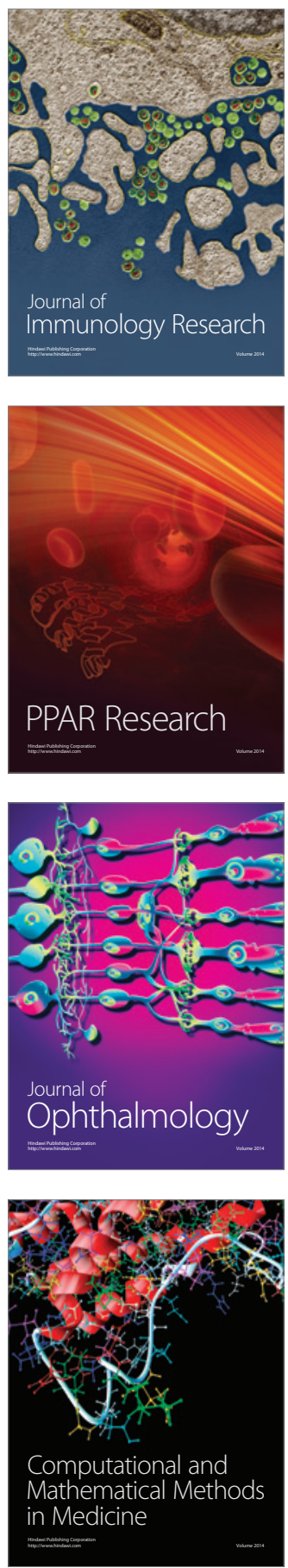

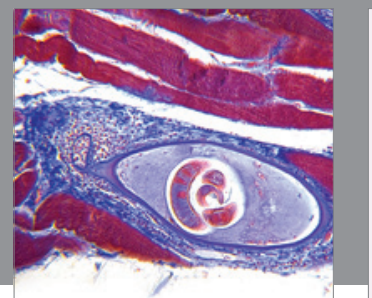

Gastroenterology

Research and Practice
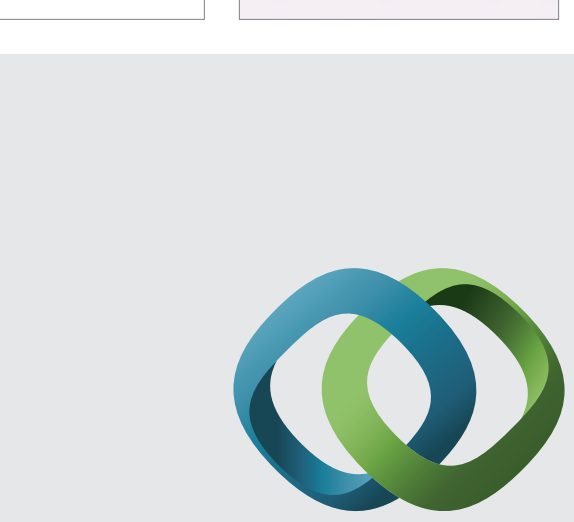

\section{Hindawi}

Submit your manuscripts at

http://www.hindawi.com
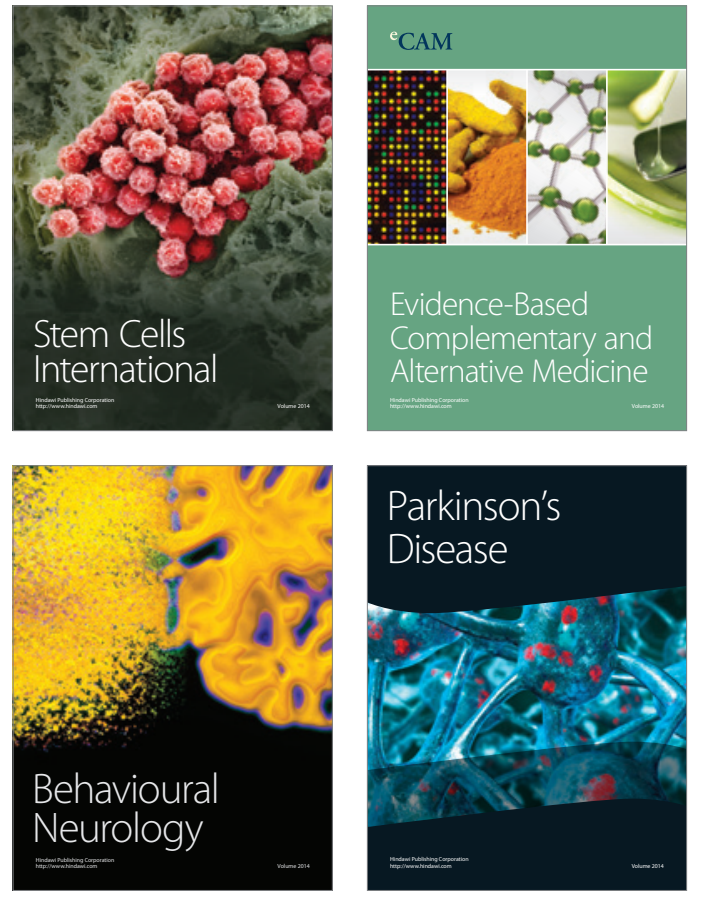
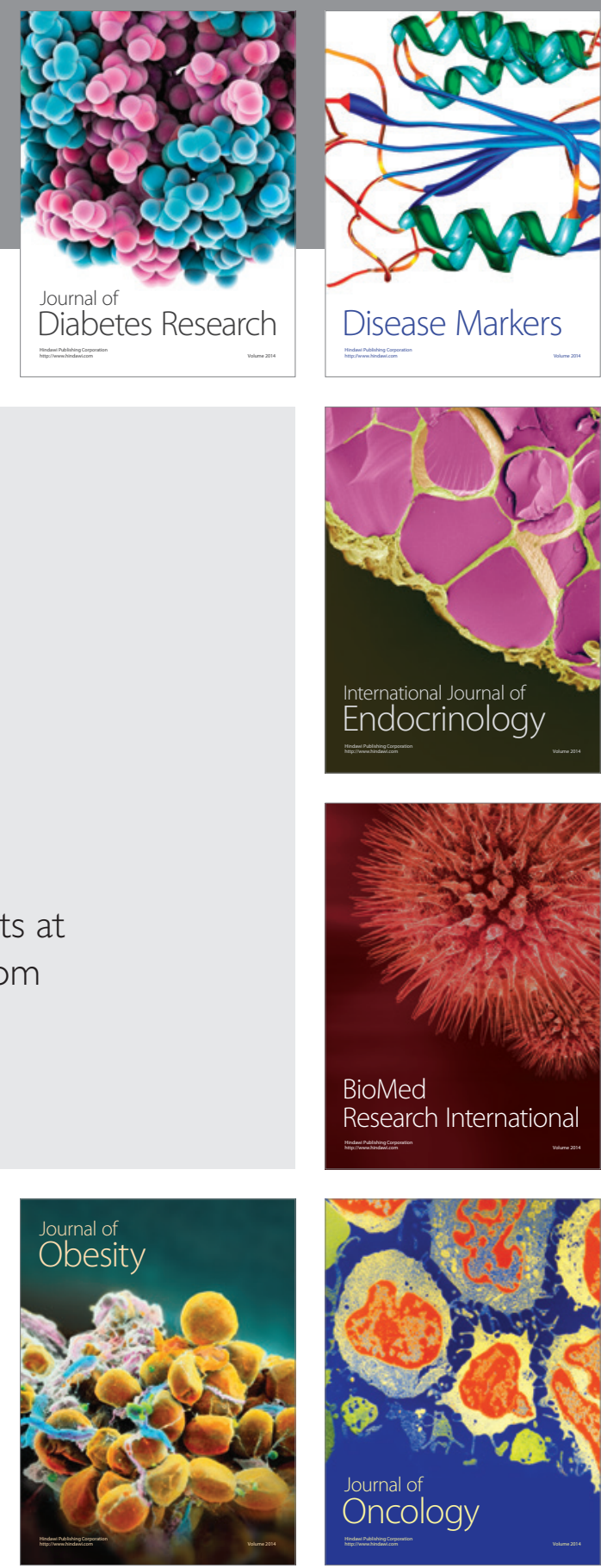

Disease Markers
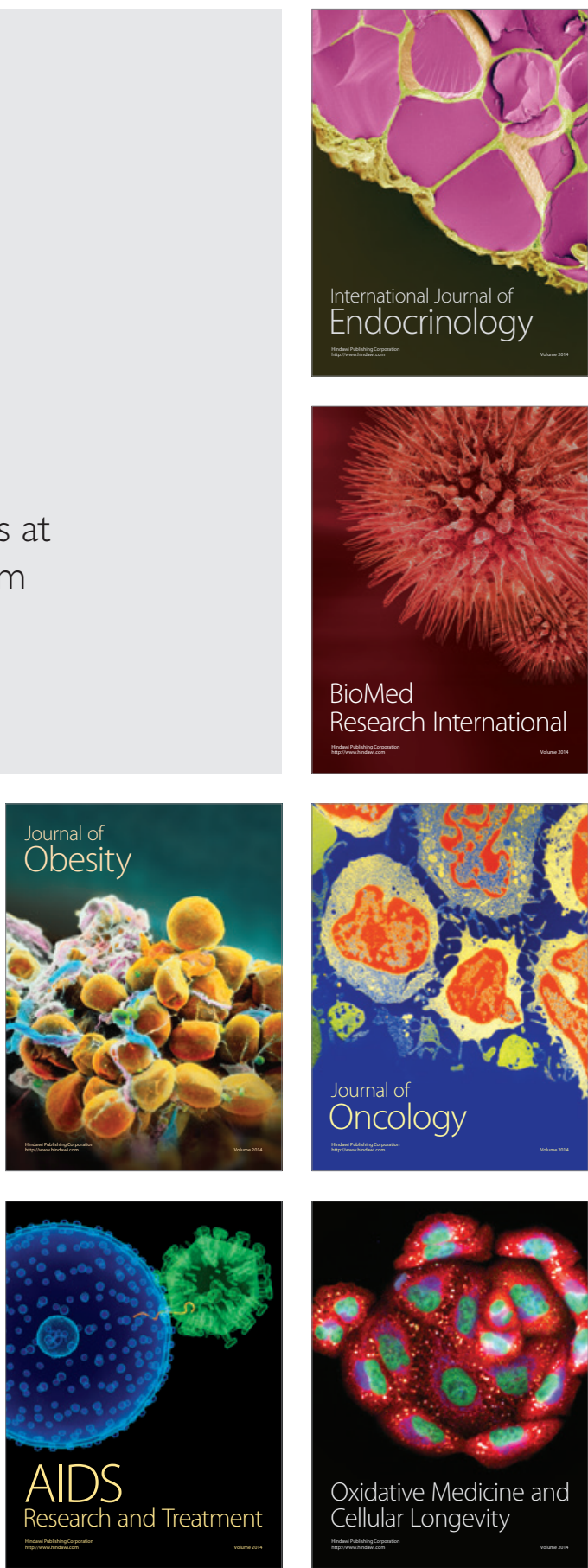